\title{
Primary mesenteric hydatid cyst
}

\author{
Jitendra Kumar Kushwaha, ${ }^{1}$ Rajni Gupta, ${ }^{2}$ Satyabrot Mohanti, ${ }^{2}$ Surender Kumar ${ }^{1}$ \\ 1Department of Surgery, CSM Medical University, Lucknow, India; \\ 2Department of Anaesthesia, CSM Medical University, Lucknow, India
}

Correspondence to Dr Jitendra Kumar Kushwaha,dr.jkkushwaha@gmail.com

\section{Summary}

Hydatid disease mostly caused by Echinococcus granulosus is a common parasitic infestation of the liver. Most common sites are liver $(70 \%)$ and lungs (25\%). Intraperitoneal hydatid cyst is found in $13 \%$ and it is usually secondary to rupture of primary hepatic cyst. Primary intraperitoeal hydatid cyst is rare (2\%). Primary hydatid cyst in mesentery is very rare. In this article, the author presents a case of primary mesenteric hydatid cyst with chronic pain in lower abdomen.

\section{BACKGROUND}

Hydatid disease is most commonly caused by Echinococcus granulosus in which humans are accidently an intermediate host. The disease occurs in the liver in $70 \%$ of cases, the lungs in $25 \%$ of cases and at other sites such as the spleen, kidney, pancreas, brain, ovary, mesentery, vertebra and soft tissue of the neck. Anaphylactic shock, cyst infection of the biliary tree and rupture into the peritoneum are the most severe complications. ${ }^{1}$ Intraperitoneal hydatid cyst is usually secondary to rupture of primary hepatic cyst. Primary mesenteric hydatid cyst is very rare. ${ }^{2}$ In this article, a case of primary mesenteric hydatid cyst in a 24 -yearold patient was presented.

\section{CASE PRESENTATION}

A 24-year-old male patient presented in hospital as pain in supra pubic area since last 1 year. Pain was increased on exertion. On examination, there was a lump in suprapubic area extending in right iliac fossa of size $(8 \mathrm{~cm} \times 7 \mathrm{~cm})$, firm, mild tender and dull on percussion.

\section{INVESTIGATIONS}

$\mathrm{Hb}-10 \mathrm{~g} \%$, total leucocyte count-8000, differential leucocyte count-P60, L20, E12, M8, B0. Liver function tests were normal. Ultrasonography report showed 'a large cystic lesion seen in retropubic space supero-anterior to bladder with triple layered wall and cysts within cyst,

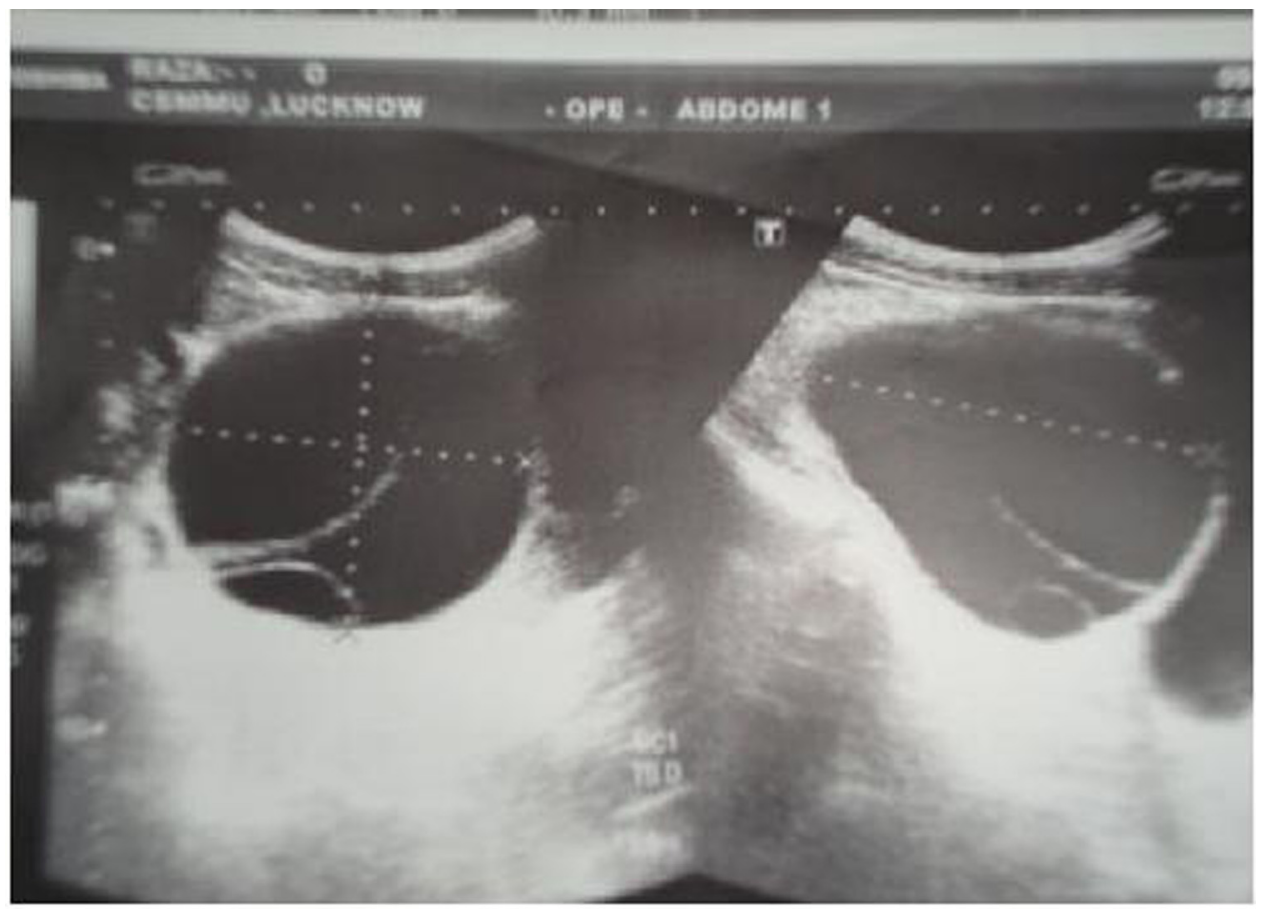

Figure 1 USG showing mesenteric hydatid cyst. 


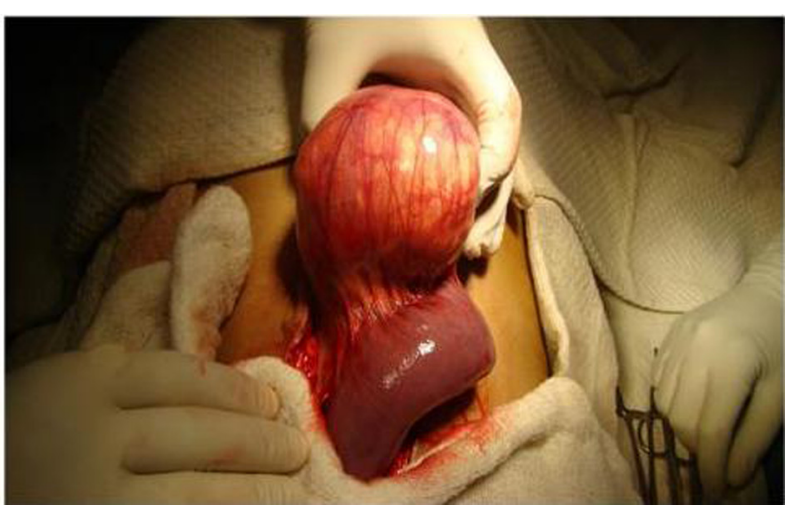

Figure 2 Peroperative picture showing mesentric hydatid cyst.

multiple small cyst also seen attached to its wall with few internal echoes suggestive of hydatid cyst' (figure 1). Liver, pancreas, spleen and other organs were normal. X-ray abdomen and chest were within normal limit. ELISA for Echinococcus was positive.

\section{DIFFERENTIAL DIAGNOSIS}

Mesenteric cyst, ileocaecal tubercular mass.

\section{TREATMENT}

Lapratomy was done after giving albendazole $400 \mathrm{mg}$ twice a day for 1 month. On exploration, it was found that there was a cyst $9 \mathrm{~cm} \times 8 \mathrm{~cm} \times 5 \mathrm{~cm}$ in mesentery of jejunum (figure 2). Liver, pancreas, spleen and other organs were normal. After instillation of $10 \%$ povidine iodine inside cyst it was completely excised. Histopathological examination report was suggestive of hydatid cyst.

\section{OUTCOME AND FOLLOW-UP}

The patient is well in follow-up.

\section{DISCUSSION}

Hydatid disease or Echinococcosis is a parasitic disease caused by infection with larva (metacestode) of the cestode echinococcus. Four species of the genus Echinococcus are known to cause infection in humans: Echinococcus granulosus (cystic hydatid disease), Echinococcus multilocularis (alveolar hydatid disease), Echinococcus vogeli and Echinococcus oligarthus (both causing polycystic hydatid disease. ${ }^{2}$ The life cycle of Echinococcus granulosus involves two hosts. The definitive host is usually a dog but may be some other carnivores. The adult worm of the parasite lives in the proximal small bowel of the definitive host, attached by hooklets to the mucosa. Eggs are released into the host's intestine and excreted in the faeces. Sheep are the most common intermediate hosts. They ingest the ovum while grasing on contaminated ground. Human become accidental intermediate host. The ovum loses its protective chitinous layer as it is digested in the duodenum. The released hexacanth embryo, or oncosphere passes through the intestinal wall into the portal circulation and develops into a cyst within the liver. When the definitive host eats the viscera of the intermediate host, the cycle is completed. Humans may become intermediate host through contact with a definitive host (usually a domesticated dog) or ingestion of contaminated water or vegetables. ${ }^{3}$ The most common site involved is the liver $(59-75 \%)$, followed in frequency by lungs $(27 \%)$, kidney $(3 \%)$, bone $(1-4 \%)$ and brain $(1-2 \%)$. Other sites such as the heart, spleen, pancreas, omentum, ovaries, parametrium, pelvis, thyroid, orbit or retroperitoneum and muscles are very rarely affected. ${ }^{4}$ Peritoneal hydatid cyst, either primary or secondary, represents an uncommon but significant manifestation of the disease (approximately 13\%). Intraperitoneal hydatid cysts are usually secondary to the rupture (spontaneous, traumatic or iatrogenic) of a primary hepatic or splenic cyst. ${ }^{4}$ Primary peritoneal echinococcosis accounts for $2 \%$ of all abdominal hydatidosis. ${ }^{5}$ Balik et al reviewed 27 patients retrospectively who were treated surgically between 1981 and 1999 because of extrahepatic hydatid disease. In which 19 patients had coexistent hepatic cyst $(70.4 \%)$ while eight patients $(20.6 \%)$ had only extrahepatic cysts located in spleen (three patients), pancreas (two patients), adrenal glands (four patients), mesocolon (five patients), mesentery of small intestine (one patient), ovaries (one patient), retroperitoneum (four patients), omentum (two patients). ${ }^{6}$ In another study, Wani et al reviewed retrospectively 183 patients of abdominal hydatid cysts managed surgically from January 1998 to December 2000, in which he found $12 \%$ patients had extrahepatic abdominal cyst. ${ }^{7}$ A solitary cyst in the mesentery can be considered primary only when no other cysts are present. In such a case, the hydatid embryo gains access to the mesentery by haematogenous or lymphatic route. Mesenteric hydatid cysts usually present as a non-specific mass, pain due to traction on mesentery and pressure effects on adjacent organs. Sometimes, they can rupture spontaneously. ${ }^{1}$ Serology and imaging are the main tools for establishing diagnosis of hydatid disease. Ultrasound is the preferred first line imaging, but contrast enhanced CT gives more precise information regarding the morphology (size, location, neighbourhood and number) of the cyst. Drug treatment with albendazole has been found to be successful in a proportion of cases, but drug therapy is generally not used as the primary treatment except in cases where the patient is not fit for surgery or the cyst size is smaller or deeply located. Surgery is the most effective treatment. Combination of preoperative albendazole therapy, surgery and postoperative albendazole therapy is a useful regime. Albendazole suppresses the development of hydatid cysts following intraperitoneal inoculation of protoscolices. ${ }^{8}$

\section{Learning points}

- Primary mesenteric hydatid cyst even rare should be included in differential diagnosis of patient presenting as pain abdomen with intra abdominal lump.

\section{Competing interests None.}

Patient consent Obtained.

\section{REFERENCES}

1. Lewall DB. Hydatid disease: biology, pathology, imaging and classification. Clin Radiol 1998;53:863-74.

2. Khuroo MS. Hydatid disease: current status and recent advances. Ann Saudi Med 2002;22:56-64. 


\section{BMJ Case Reports}

3. Pedrosa I, Saíz A, Arrazola J, et al. Hydatid disease: radiologic and pathologic features and complications. Radiographics 2000;20:795-817.

4. Yuksel M, Demirpolat G, Sever A, et al. Hydatid disease involving some rare locations in the body: a pictorial essay. Korean J Radiol 2007;8:531-40.

5. Singh RK. A case of disseminated abdominal hydatidosis. J Assoc Physicians India 2008:56:55.
6. Balik AA, Celebi F, Ba glu M, et al. Intra-abdominal extrahepatic echinococcosis. Surg Today 2001;31:881-4.

7. Wani RA, Malik AA, Chowdri NA, et al. Primary extrahepatic abdominal hydatidosis. Int J Surg 2005;3:125-7.

8. Parray F0, Ahmad SZ, Sherwani AY, et al. Primary paraspinal hydatid cyst: a rare presentation of Echinococcosis. Int J Surg 2010;8:404-6.

This pdf has been created automatically from the final edited text and images.

Copyright 2012 BMJ Publishing Group. All rights reserved. For permission to reuse any of this content visit

http://group.bmj.com/group/rights-licensing/permissions.

BMJ Case Report Fellows may re-use this article for personal use and teaching without any further permission.

Please cite this article as follows (you will need to access the article online to obtain the date of publication).

Kushwaha JK, Gupta R, Mohanti S, Kumar S. Primary mesenteric hydatid cyst. BMJ Case Reports 2012;10.1136/bcr.03.2012.5996, Published XXX

Become a Fellow of BMJ Case Reports today and you can:

- Submit as many cases as you like

- Enjoy fast sympathetic peer review and rapid publication of accepted articles

- Access all the published articles

- Re-use any of the published material for personal use and teaching without further permission

For information on Institutional Fellowships contact consortiasales@bmjgroup.com

Visit casereports.bmj.com for more articles like this and to become a Fellow

Keep up to date with all published cases by signing up for an alert (all we need is your email address) http://casereports.bmj.com/cgi/alerts/etoc 